\title{
Meridional Considerations of the Centrifugal Compressor Development
}

\author{
C. Xu and R. S. Amano \\ Department of Mechanical Engineering, University of Wisconsin, Milwaukee, WI 53211, USA \\ Correspondence should be addressed to R. S. Amano, amano@uwm.edu
}

Received 29 January 2012; Accepted 4 September 2012

Academic Editor: A. Engeda

Copyright (๑) 2012 C. Xu and R. S. Amano. This is an open access article distributed under the Creative Commons Attribution License, which permits unrestricted use, distribution, and reproduction in any medium, provided the original work is properly cited.

Centrifugal compressor developments are interested in using optimization procedures that enable compressor high efficiency and wide operating ranges. Recently, high pressure ratio and efficiency of the centrifugal compressors require impeller design to pay attention to both the blade angle distribution and the meridional profile. The geometry of the blades and the meridional profile are very important contributions of compressor performance and structure reliability. This paper presents some recent studies of meridional impacts of the compressor. Studies indicated that the meridional profiles of the impeller impact the overall compressor efficiency and pressure ratio at the same rotational speed. Proper meridional profiles can improve the compressor efficiency and increase the overall pressure ratio at the same blade back curvature.

\section{Introduction}

High single-stage pressure ratio and high performance are greatly desired in the design of the centrifugal compressors. High boost pressure of aircraft engine and diesel engines, and equipment cost in the oil and gas fields require high pressure ratio and improved thermal efficiency single-stage centrifugal compressors. The manufacturers of marine turbochargers also have been competing for the development of high pressure compressors. The demands for a high pressure ratio for centrifugal compressors need special consideration during the compressor design. If the centrifugal single-stage compressor ratio is over 4.5, the flow of the impeller exit normally has a supersonic zone. This makes the high pressure ratio centrifugal compressor design very challengeable.

The centrifugal compressor design has been an active research field for many years [1-4]. Unlike axial compressors, gas enters a centrifugal compressor axially and then turns in the radial direction out from the impeller with the action of the centrifugal force. The gas then is directed to a radial annular vaned or vaneless diffuser and finally moves into a volute or collector to deliver the compressed gas to the next stage or send it to the next components [1-7]. Unlike an axial compressor or fan [8], the work input for a centrifugal compressor is almost independent of the nature of the flow. A centrifugal compressor can be designed with much higher De Haller number than an axial compressor can achieve. Therefore, it is possible for a centrifugal compressor to have a much higher stage pressure ratio than an axial one. In addition, centrifugal compressors show very reasonable performance at low flow gas compression.

The development of computer technologies and advancements in turbomachinery technology have made optimizing the centrifugal compressor design possible and easier than ever before. Turbomachinery design normally starts with a mean line program at each individual operating point on a map and then through-flow calculation is performed; finally, the impeller, diffuser, and volute are designed. It is also important to optimize off-design performance.

Recently, multidiscipline optimizations have drawn more attention. Due to the complications of the engineering system and of multidisciplines, it is still challenging. He and Wang [9] developed a process for an adjoined approach to concurrent blading aerodynamic and aero-elastic design optimizations at earlier stages of the design process. A nonlinear harmonic phase solution method is adopted to solve the unsteady Reynolds-averaged Navier-Stokes (RANS) 


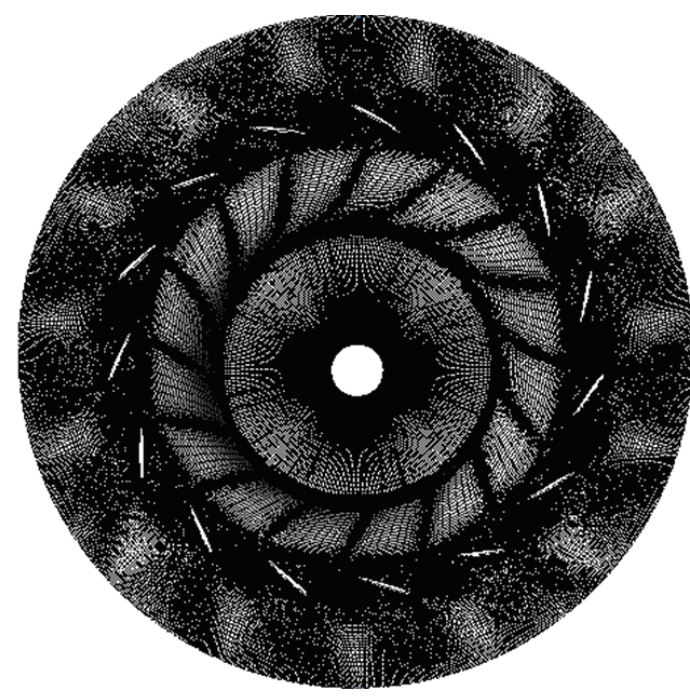

(a) Overview of the 360 degree mesh

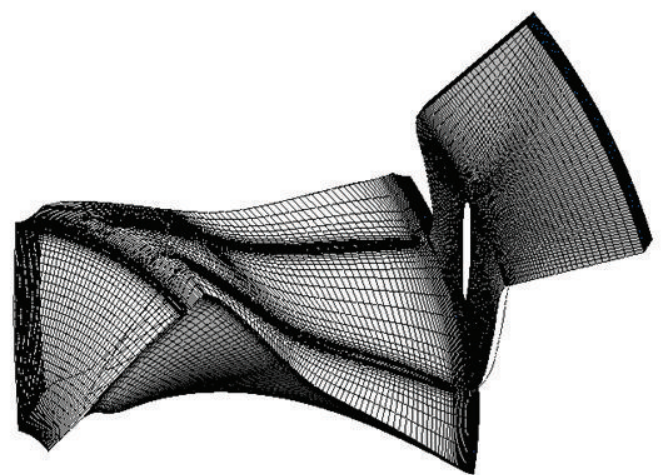

(b) Single sector mesh

Figure 1: Calculation meshes.

equations to enhanced interactions between the blades and the surrounding working fluid. Thus, a blade flutter stability and forced response are possible to obtain. Ghisu et al. [10] recently developed a system for the integrated design optimization of gas turbine engines; postponing the setting of the interface constraints to a point facilitates better exploration of the available design space and better exploitation of the tradeoffs between different disciplines and modules. Verstraete et al. [11] developed a multidisciplinary optimization system and used it to design a small radial compressor impeller. The method only discussed the aerodynamic performance and stress interactions. However, the impeller reliability not only relied on the stress but also on the vibrations, that is, low-cycle fatigue (LCF) and high-cycle fatigue ( $\mathrm{HCF})$.

In this study, a recently developed turbomachinery viscous aerodynamic and structure optimal method $[4,12-$ 18] was used to fully optimize a centrifugal compressor design. The main focus of this study lies in emphasizing the importance of the meridional shape related to a centrifugal compressor aerodynamic performance. The designs reported here all met the structure requirements for different meridional shapes. The results showed that the meridional shape is very important for obtaining an optimized impeller design.

To demonstrate the meridional impacts on the compressor performance, a compressor with an inlet flow of $34 \mathrm{Nm}^{3} / \mathrm{min}$ was used in analyses. The design point is with the conditions of the polytropic head and the flow coefficients of $\varphi=0.68$, and $\phi=0.195$, respectively. The design total pressure ratio is about 4.45 . The impeller inducer average Mach number is about 0.85 and the average exit Mach number is about 1.08. Therefore, the compressor has a significant supersonic range. The design considered a transonic range and efforts to reduce the shock loss. The diffuser vane was designed by few patent features and was not changed during the impeller optimization [19].
The compressor design employs the present design process that includes a viscous aerodynamic design and structure optimization for achieving efficiency and stability targets. The compressor developed in this study consists of three major parts: an impeller, a low solidity diffuser, and a volute. In this study, particular attention was paid to the impeller meridional design to illustrate the importance.

\section{CFD Calculations and Validations}

The commercial computational fluid dynamics (CFD) code ANSYS CFX-11.0 [20] was used for the calculations. The mesh independent studies found out that the mesh sizes as shown in Figures 1 and 2 were sufficient to keep the identical performance even as the mesh continued to refine. The calculation nodes for the 360 degree wheel are about 2 million and the diffuser nodes are about 6 million. The single sector wheel nodes are about $250 \mathrm{k}$ and the diffuser is about $400 \mathrm{k}$. The mesh near wall has been set as the $\mathrm{y}+$ value smaller than 2.5. The fluid models use ideal gas and heat transfer calculations with total energy to include the viscous work term in the heat transfer calculation, along with the $\mathrm{k}-\varepsilon$ turbulence model. An existing compressor stage was calculated and compared with the test results to validate the CFD process and the mesh independent status [21]. The mesh structures are shown in Figures 1 and 2. Three different calculations were performed, that is, 360 degree mixing plane vane and rotor interface, 360 degree frozen rotor vane and rotor interface, and single sector frozen rotor vane and rotor interface. The test runs for the frozen rotor interface showed that the vane and wheel blade relative location affects the calculated performance results. Several different rotor and vane locations were run for a single slide of the rotor and the vane. We found that the relative location between the vane and the wheel blade, as shown in Figure 1(b), provided the performance results most close to the experiments. It 


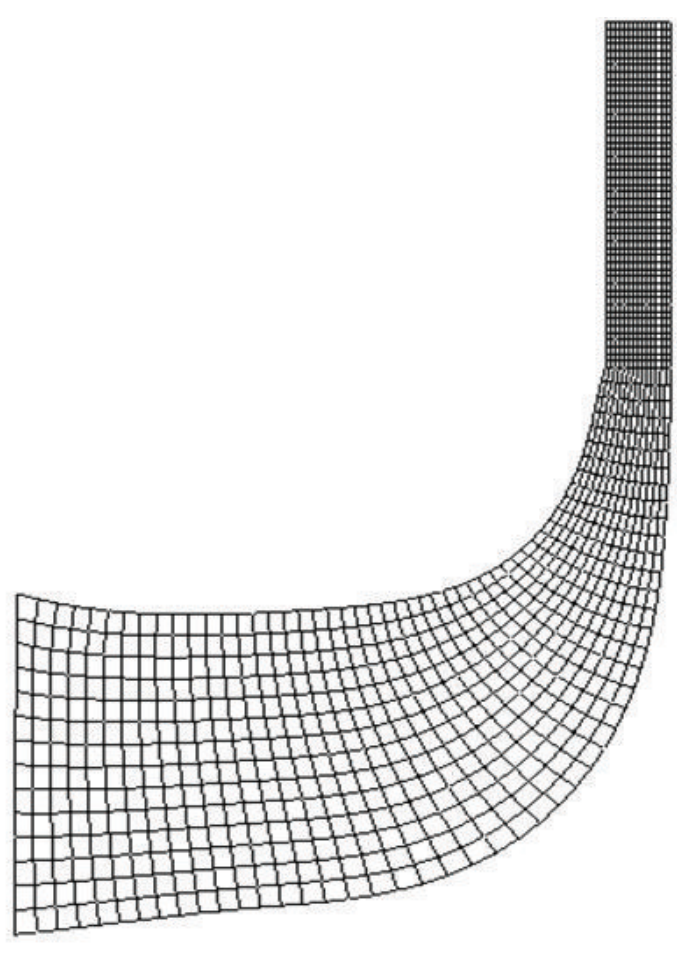

(a) Meridional view

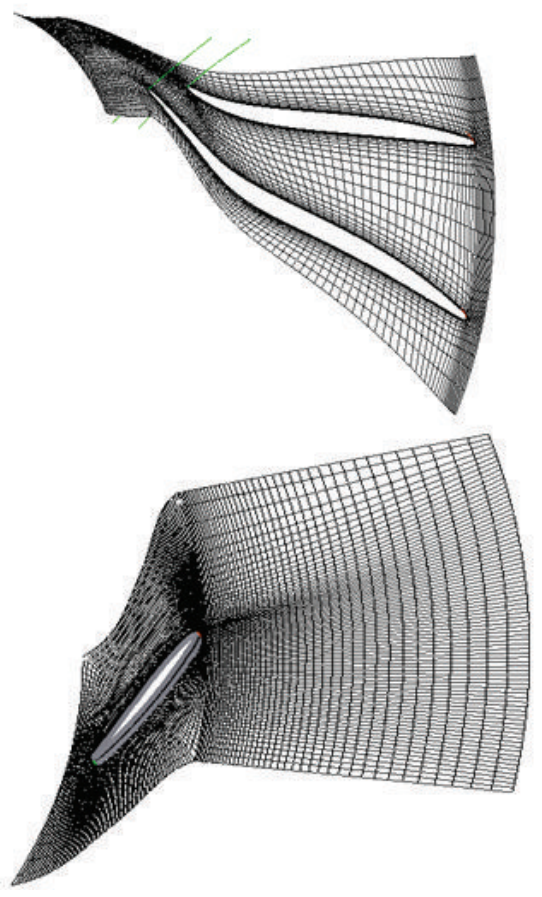

(b) Blade to blade view

FIgURE 2: Mesh in meridional view and blade to blade view.

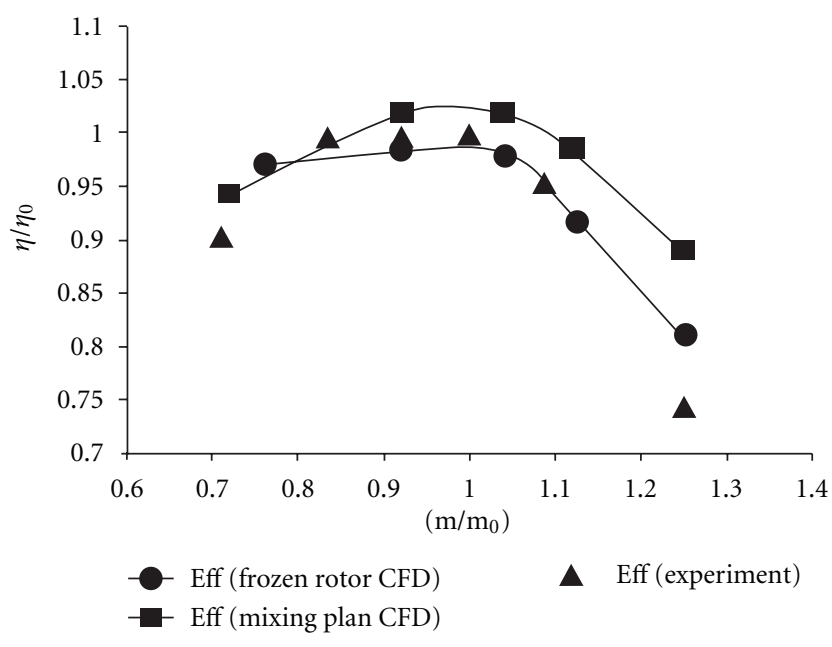

(a) Efficiency versus flow.

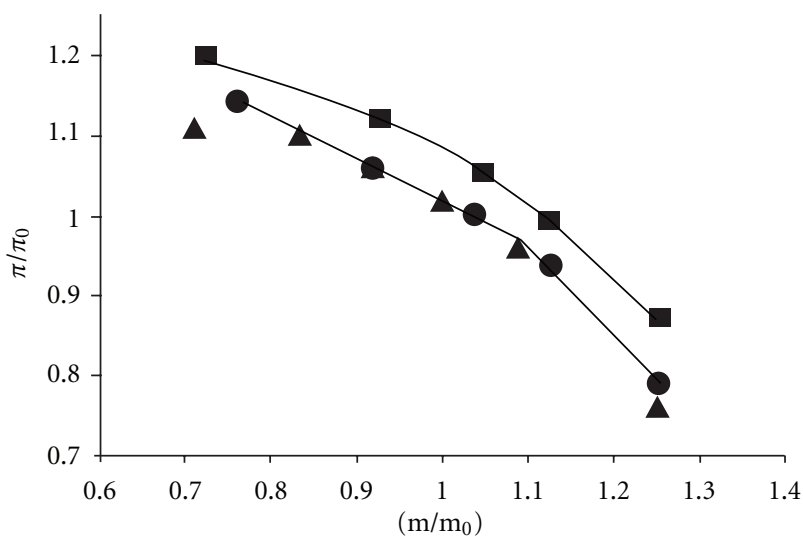

- PR (frozen rotor CFD)

PR (mixing plan CFD)

(b) Pressure ration versus flow

FIgURE 3: Computational results compared with experiments.

is implied that the frozen rotor calculation from this wheel and vane location is close to the unsteady time average results. During the calculations, we found that the calculated performance results were almost identical for the 360 degree frozen rotor compared with the single sector frozen rotor vane, as shown in Figure 1(b). The CFD results with volute loss corrections are shown in Figure 3, where it is clearly shown that both the frozen rotor and the mixing plane calculations provided a good indication of experiments. The frozen rotor with a single sector of the blade and vane provided the results very close to the experiments. All the analyses in the study of meridional shape impacting the performance were performed with the single sector with a frozen rotor interface. 


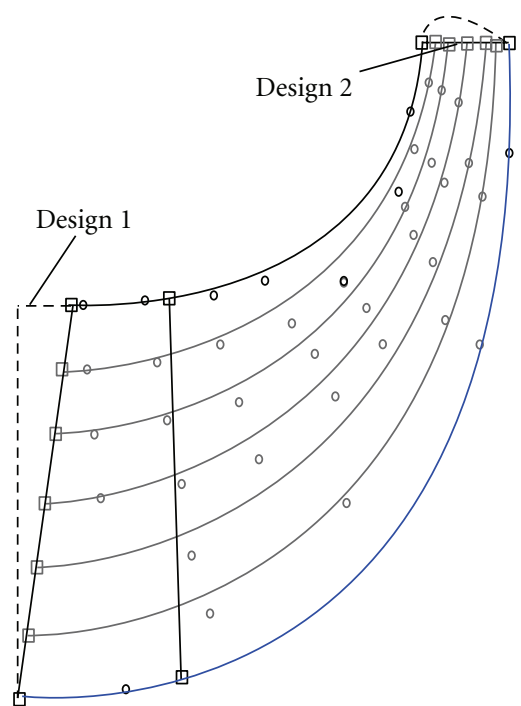

(a) Meridional view of the two designs

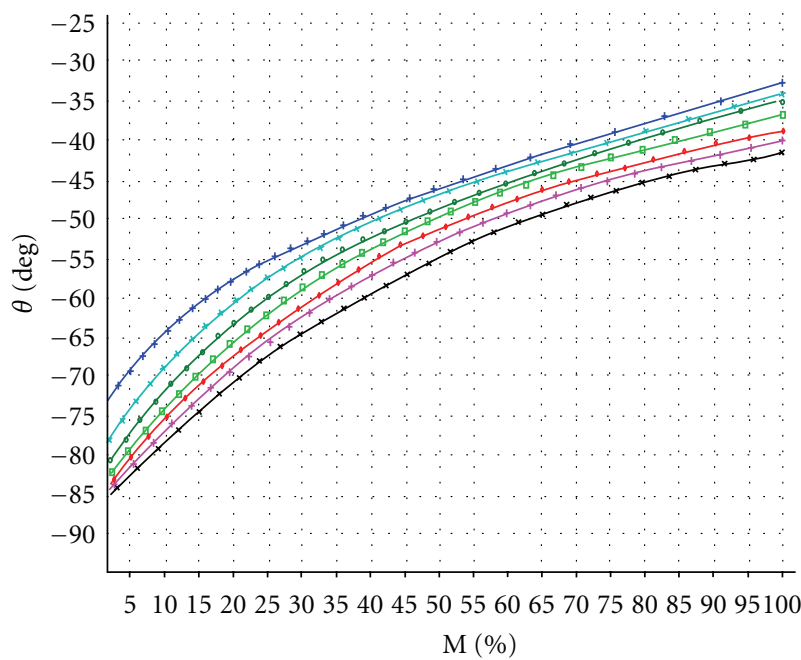

(b) Blade angle distributions along the meridional length

Figure 4: Geometry of Design 1 and Design 2.

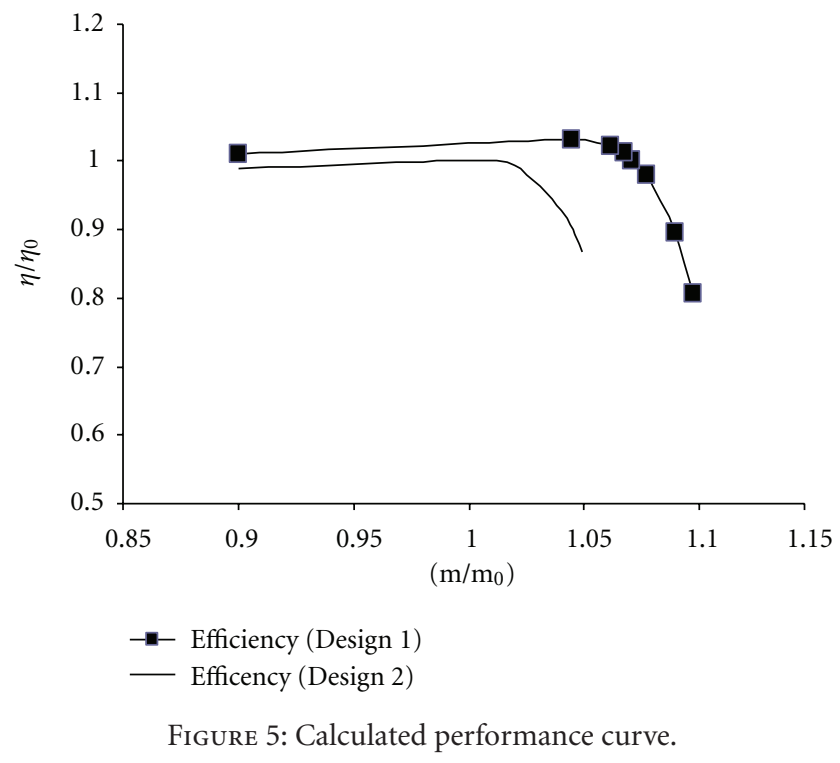

\section{Results and Discussion}

In this study, the focus is to study the meridional shape impact on the centrifugal compressor performance. During the study, the impeller blade angle changes with the percentage of the meridional distance being maintained the same, while the meridional shape was changed, as shown in Figure 4. The vane design was kept the same for both Design 1 and Design 2 to demonstrate the impeller impact on the overall stage performance. Figure 4(a) highlighted the difference between the two meridional shapes. Design 1 is a newly proposed meridional shape with a vertical inlet and an exit with a clipped, smooth-curved shape. Design 2 is the traditional meridional design with an inlet tip cut back and a flat discharge. Figure 4(b) shows the blade angle $\beta$ distribution along the nondimensional meridional length.

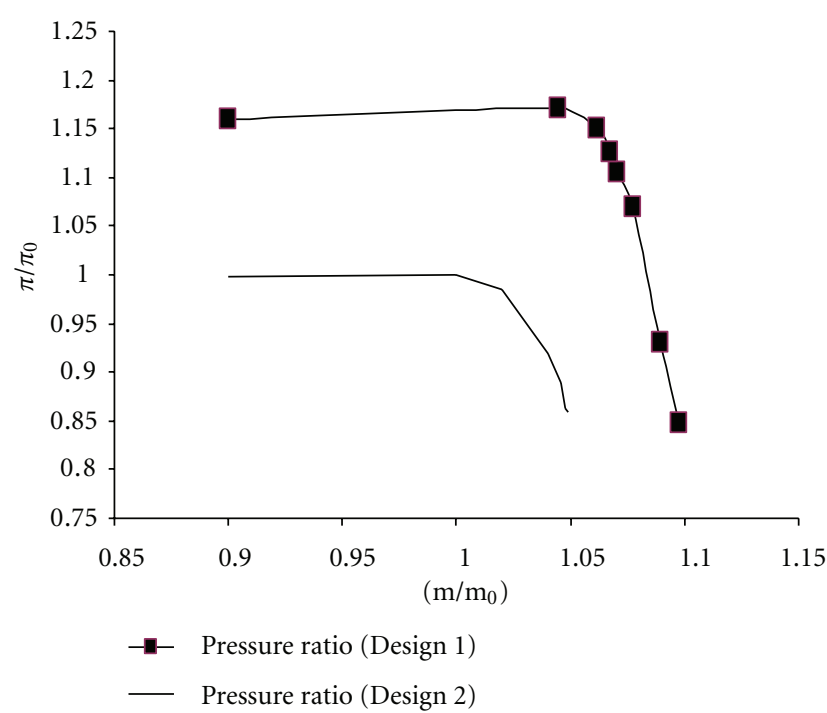

FIgURE 6: Calculated pressure ratio.

Both designs have the identical $\beta$ distributions. During the calculations, a similar mesh size was used for all the studies as presented in the previous section to ensure that the results were mesh-independent.

Calculations indicated that Design 1 had a relative higher efficiency and wider operating range, as shown in Figure 5. This is because the shroud section has a more general distribution of the blade loading. Also, both the shroud side and the hub side have a similar pressure raise along the meridional direction, which reduced the flow mixing loss between the shroud and the hub at the impeller exist. The design intention was to make a uniform distribution of the impeller exit static pressure. The analysis also indicates that, Design 1 has a higher pressure ratio compared with Design 2, as shown in Figure 6. Design 1 shows about a 15\% higher 


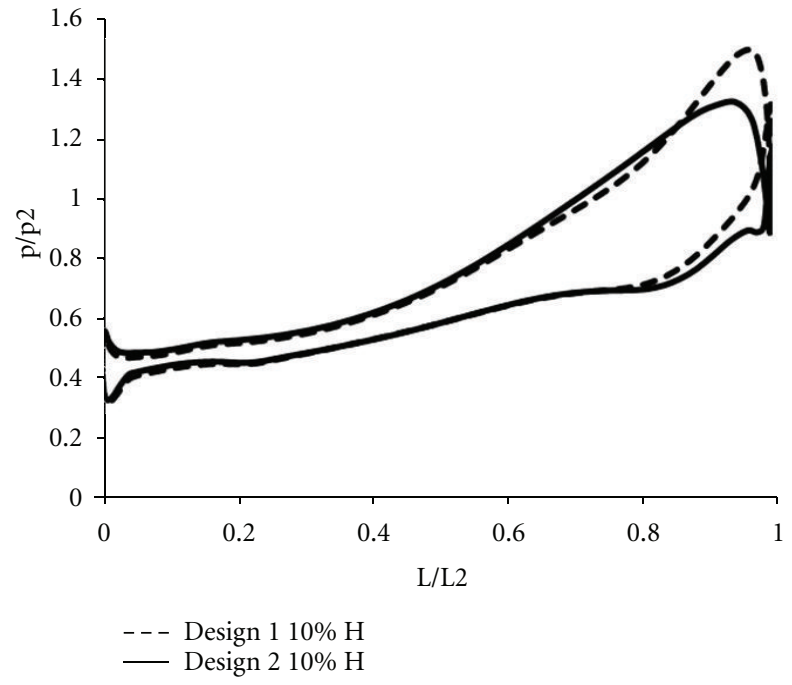

(a) Blade loading at $10 \% \mathrm{H}$

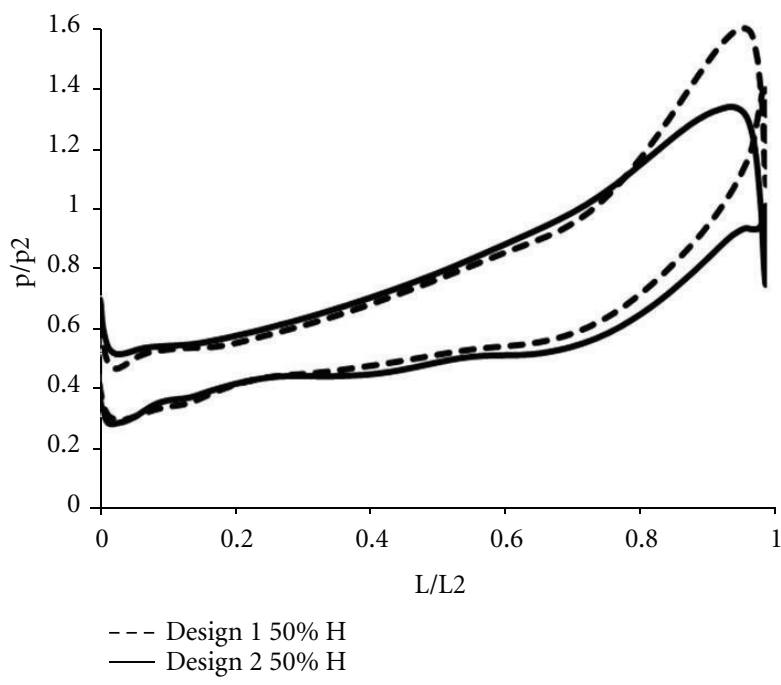

(b) Blade loading at $50 \% \mathrm{H}$

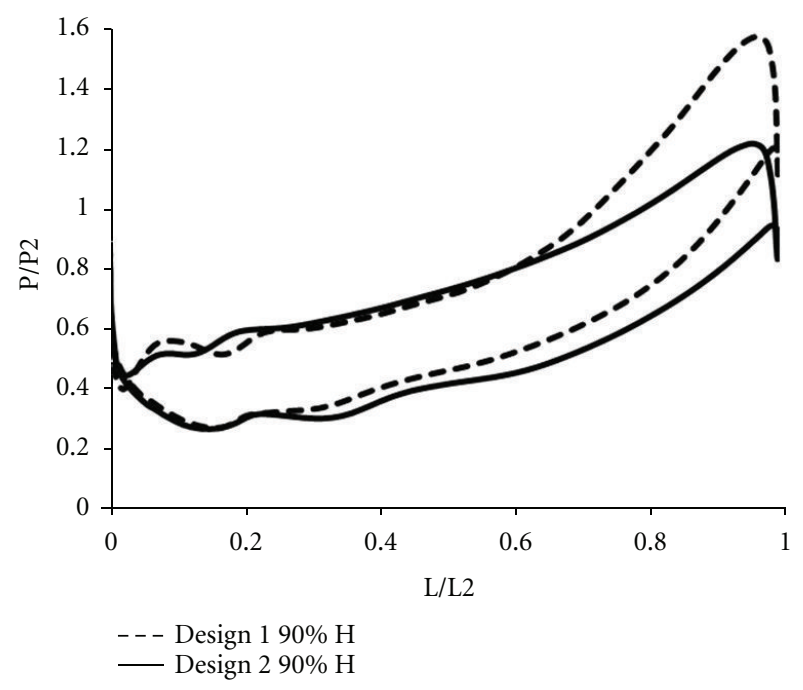

(c) Blade loading at $90 \% \mathrm{H}$

FIgURE 7: Blade loading at different blade height locations.

pressure ratio compared with Design 2. This is because in Design 1 the exit shroud has a larger diameter. The increase of the exit diameter raises the pressure ratio. The increase of the shroud impeller exit diameter also increases the overall flow capacity, as shown in both Figures 5 and 6. However, the calculations show that the surge flow does not change too much. This is because Design 1 has a better flow control that delayed the flow separation and surge.

Figure 7 shows the blade loading (p/p2) distributions along different spanwise locations. For all the blade spanwise locations, Design 1 shows a higher loading than Design 2 at the impeller exit. The loading profiles indicate that the two designs have a similar loading below $80 \%$ meridional direction. For Design 1, the shroud loaded more than for Design 2. Figure 7 also shows that the shroud static pressure is close to the hub static pressure for Design 1. However, the loading plots of Design 2 show that the shroud static pressure is lower than that for the hub side. The results indicate that the flow at the exit has a higher mixing loss.

Figure 8 shows the Mach number distributions for the impeller and the vane at different spanwise locations for both Design 1 and Design 2 near the peak efficiency flow condition. It can be seen also that the Mach number at the inlet of Design 1 is slightly higher than that for Design 2. This is because Design 1 has a higher mass flow rate at the design point. The larger inlet mass flow also increases the vaned diffuser inlet Mach number for Design 1. It can be seen that for the tip and midsections, separation zones (very low Mach number zone) are smaller for Design 1 than for Design 2. The small separation zones reduce loss and improve efficiency. 


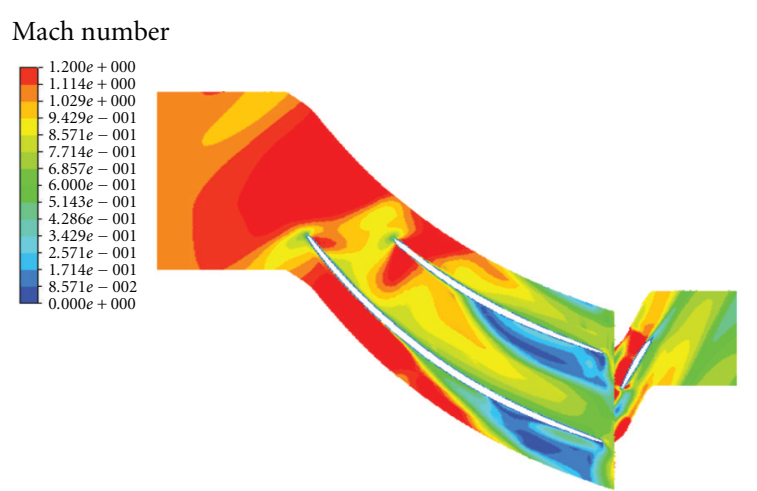

$90 \%$ span section
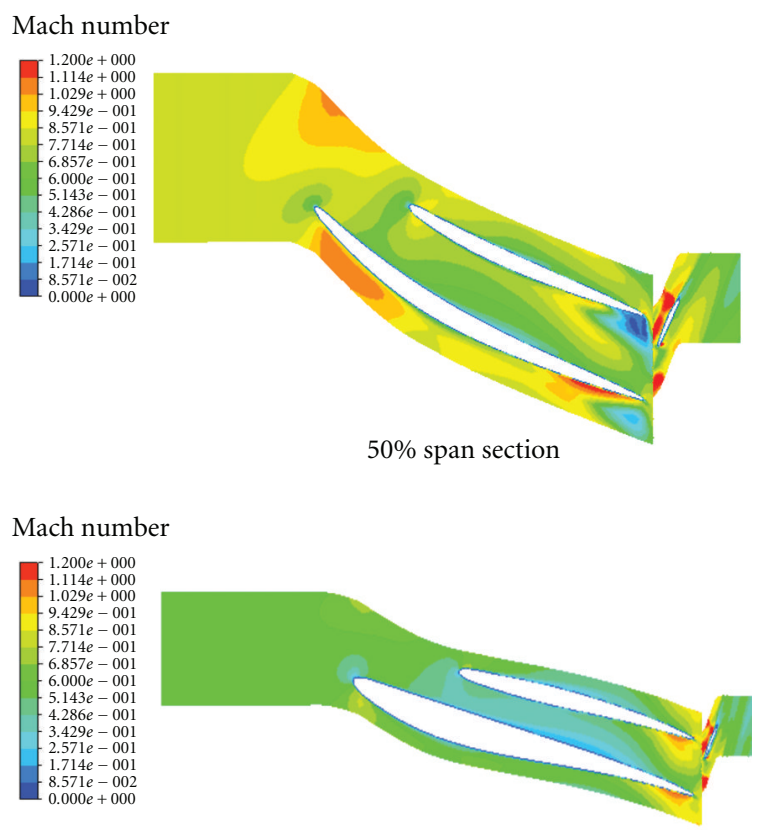

$10 \%$ span section

(a) Design 1
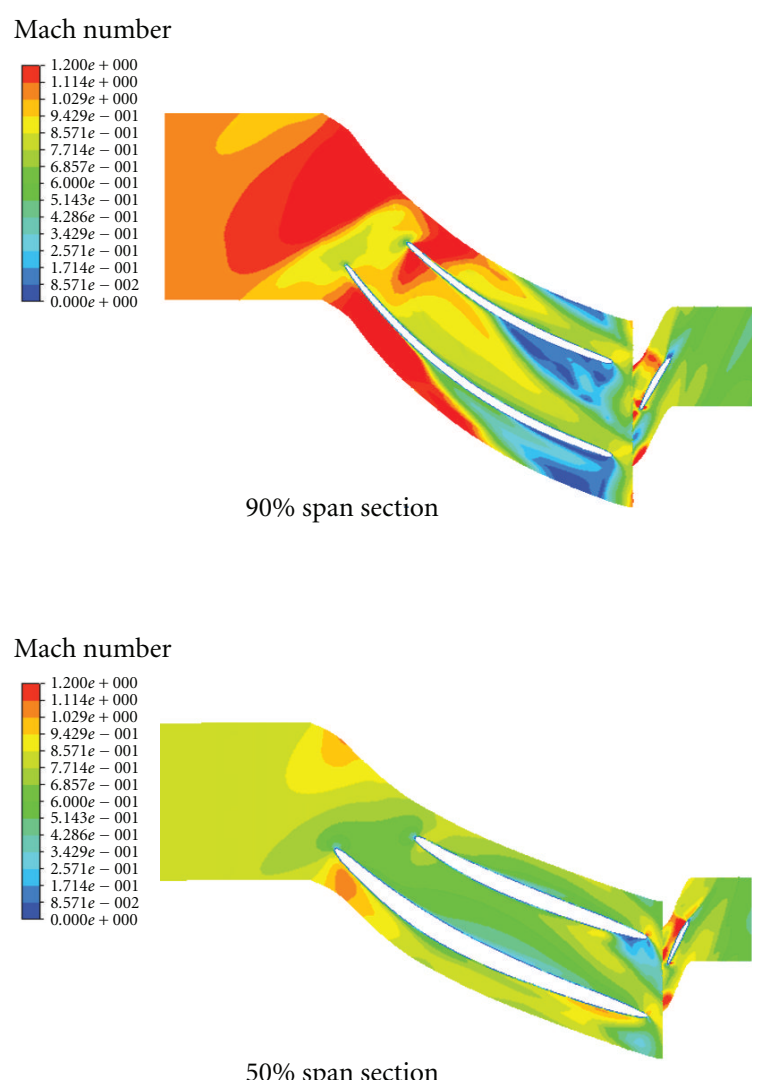

Mach number
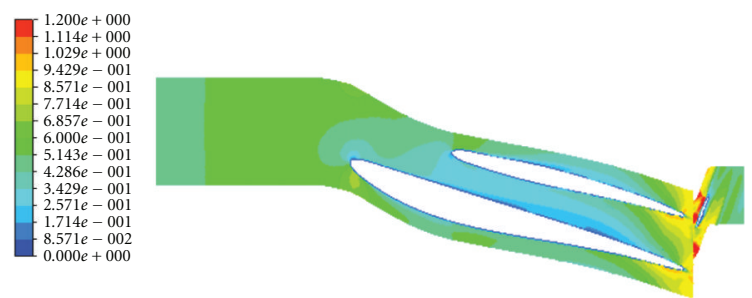

$10 \%$ span section

(b) Design 2

FIgURE 8: Mach number distributions near peak efficiency in blade to blade sections.

It is also shown that the incidents at different spanwise locations for Design 1 are smaller than those for Design 2.

Figure 9 shows the entropy contour plots for both Design 1 and Design 2 near the peak efficiency points at different spanwise locations. The high entropy area at the tip section for Design 1 is smaller than that in Design 2. However, the high entropy zone for the midspan and the hub section is similar for both designs. It can be seen that the meridional shape for Design 1 has improved the tip range of the flow. This is probably the main reason for the meridional design for Design 1 to improve the overall stage performance. Figure 10 shows the entropy generation inside the tip clearance for both Design 1 and Design 2. It can be seen that the entropy generation patterns are similar at the tip sections for both designs. Design 1 indicates a lower entropy generation at the tip area than for Design 2. Design 1 can improve the tip clearance flow and has less secondary flow loss. Figure 11 shows the entropy generation along the meridional mid-plane. It can be seen that the shroud turning location has the highest entropy generations for both designs. Design 1 has lower entropy generation near the shroud tip area compared with Design 2. It can be seen that Design 1 has some advantages compared with Design 2.

Figures 12(a) and 12(b) show the Mach number distributions at a design point along the meridional plane for both designs. It can be seen that the Mach number distributions are very similar for both designs. It is shown that the flow field distributions for both designs are in a similar pattern. This is because the flow field was basically determined by the blade $\beta$ angle distribution. However, a similar level of 

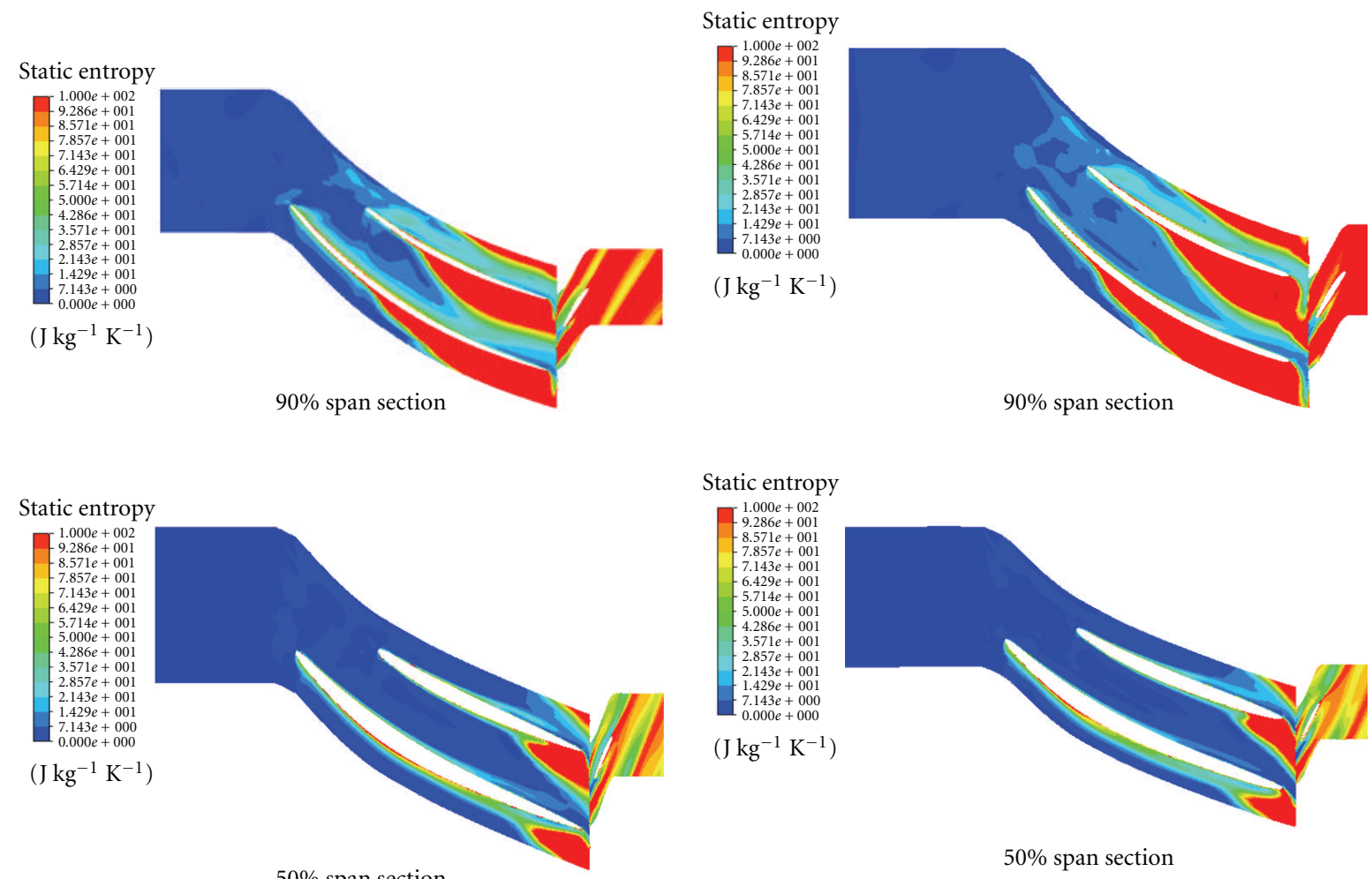

$50 \%$ span section

$50 \%$ span section
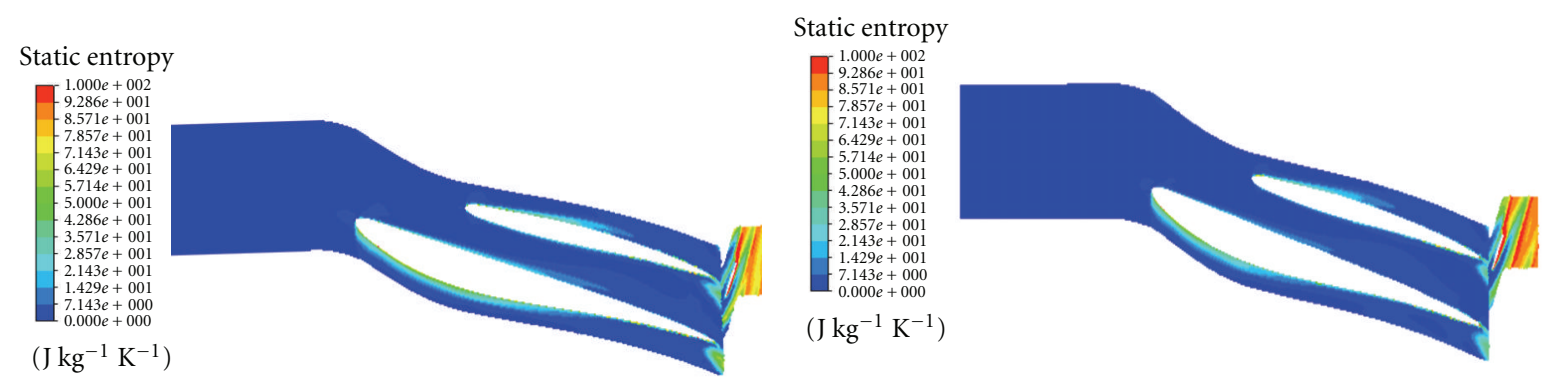

$10 \%$ span section

$10 \%$ span section

(a) Design 1

(b) Design 2

FIGURE 9: Entropy generation along the blade to blade sections.

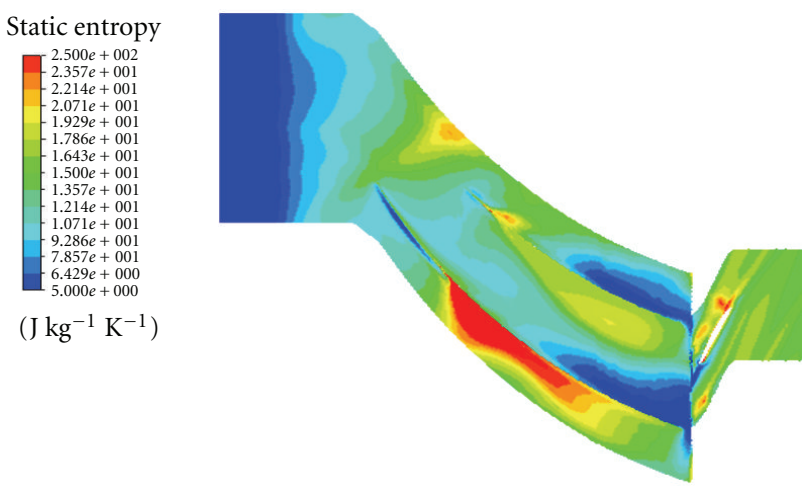

(a) Design 1

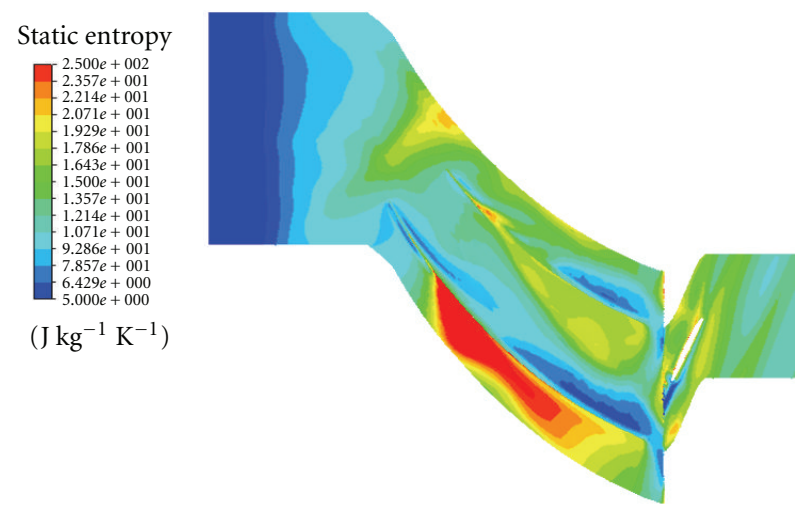

(b) Design 2

FIGURE 10: Entropy generation inside of the tip clearance (99\% span). 


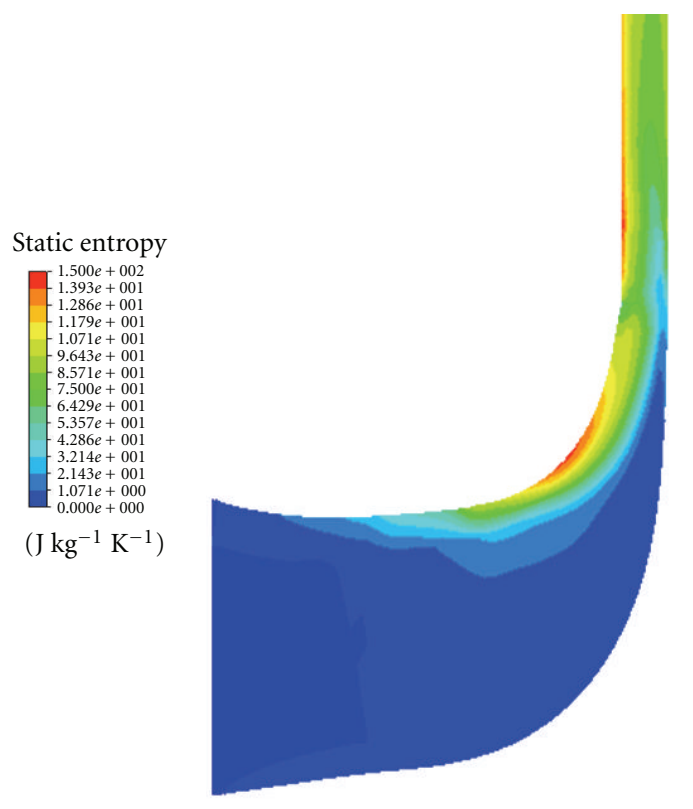

(a) Design 1

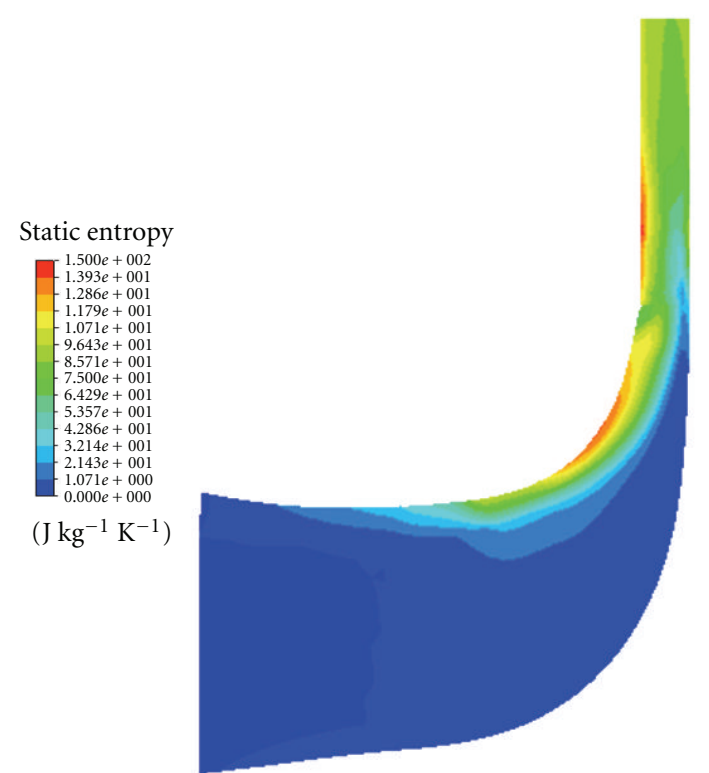

(b) Design 2

FIGURE 11: Entropy generation along the meridional plane.

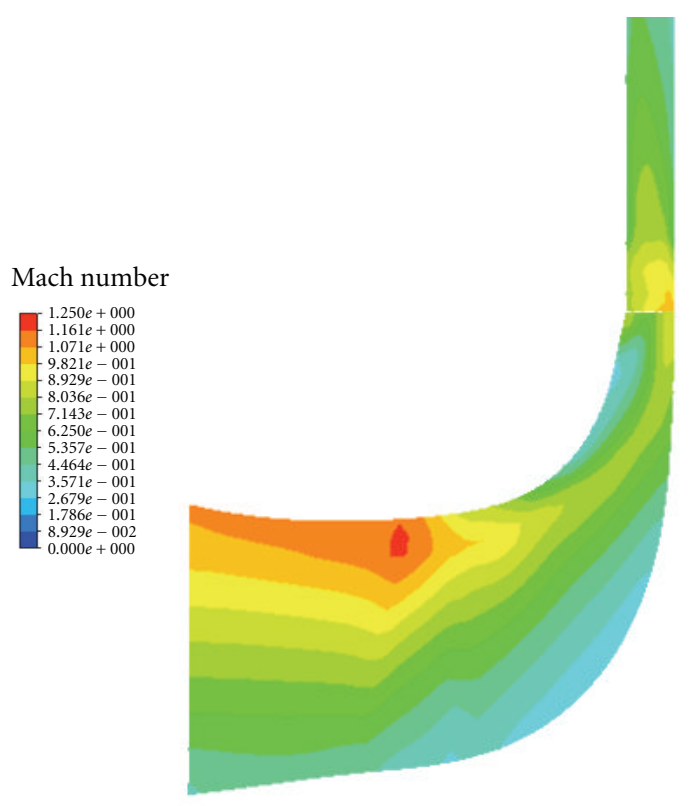

(a) Design 1

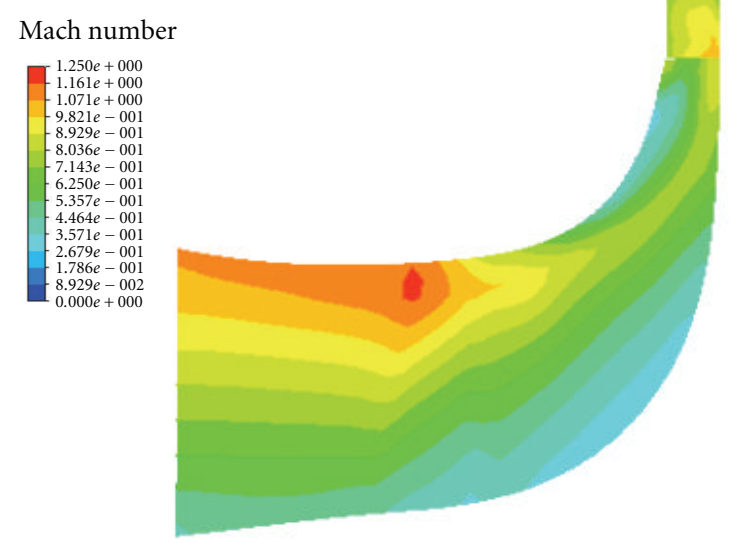

(b) Design 2

FIGURE 12: Mach number distributions at design point along the meridional plane.

Mach numbers for both designs have different level of static pressure, as shown in Figure 7 and also in Figures 13(a) and 13(b) due to the difference of the mass flow rate. Figures 13(a) and 13(b) also indicate that the static pressure has similar patterns but Design 1 has a little higher impeller exit pressure compared with Design 2. Figures 12 and 13 show that the meridional mid-plane flow structures are mainly determined by blade $\beta$ angle distributions and the hub and shroud contour shape.
Figure 14 shows the analyses for the clearance sensitivities for both Design 1 and Design 2. Both the nondimensional compressor efficiency and the pressure ratio used the design clearance (about 5.3\% B2) as a denominator. It can be seen that for both the pressure ratio and the compressor efficiency, Design 1 is less sensitive than Design 2. The analyses also indicated that the pressure ratios are more sensitive than the stage efficiency. This is because Design 1 has smaller losses near the shroud, as shown in Figure 9. 


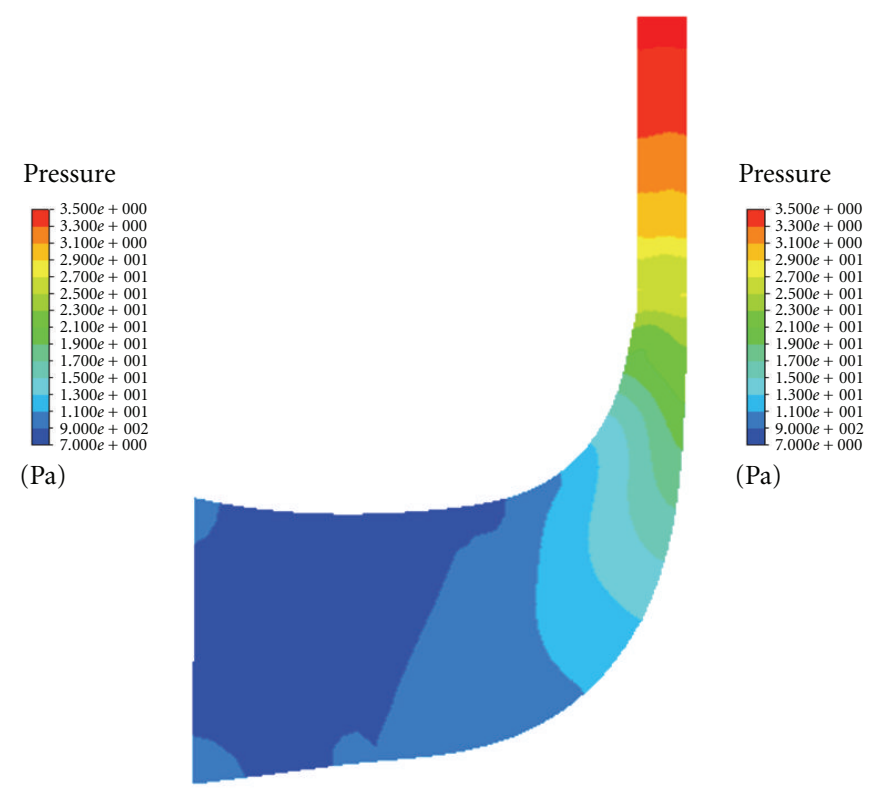

(a) Design 1

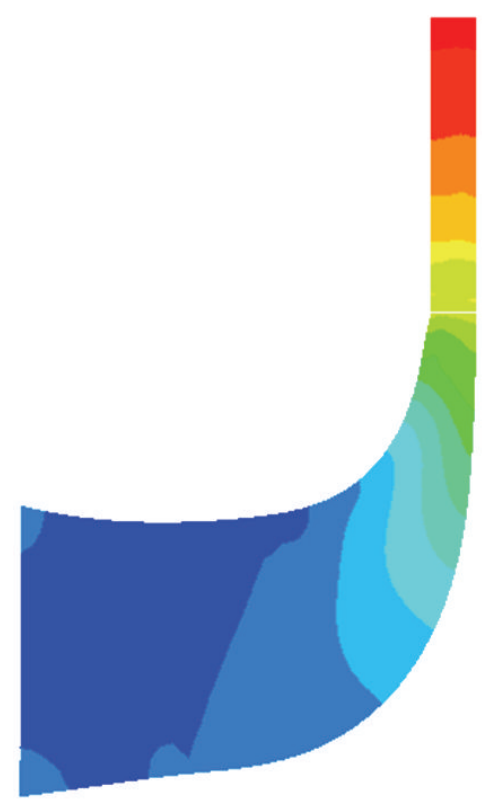

(b) Design 2

FIGURE 13: Static pressure distributions at design point along the meridional plane.

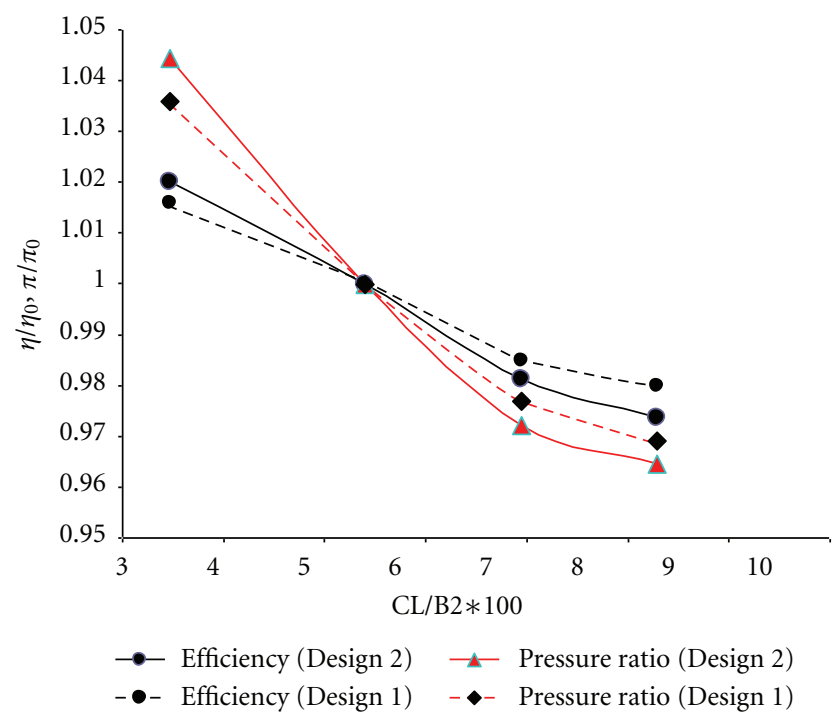

FIGURE 14: Clearance sensitivity.

\section{Conclusions}

This research provides an important study of the meridional features of the centrifugal impeller design. Very little information has been available that provides insights into the importance of the compressor meridional plane at the inlet and the exit of the impeller in the open literature. This study shows that a proper design for the inlet and the exit of the meridional plane can improve the compressor's overall efficiency and also can reduce the sensitivity of the tip clearance. This study further shows that the meridional plane of the inlet and the exit similar to Design 1 can improve the flow field near the shroud and improve the overall impeller efficiency. This study also indicates that without changing the other components of the compressor stage, optimization of the impeller meridional shape can improve the compressor stage efficiency and the pressure ratio. This study also provides the upgrading possibilities for compressor manufacturers to make a slight change of the impeller inlet and the exit shape from the old design to improve the compressor's performance. Finally, this study suggests that the impeller design not only needs to optimize the blade angle distributions, but also needs to optimize the meridional plane. 


\section{Nomenclature}

$B: \quad$ Impeller exit of diffuser width

$K$ : $\quad$ Turbulence kinetic energy

CL: Clearance

$C: \quad$ Total velocity

$C_{\theta}: \quad$ Velocity component in rotating direction

D2: Impeller exit diameter

RMR: $M r 1 / M r 2$

$u$ : $\quad$ Rotating velocity

$w$ : Relative velocity

D: Diameter of impeller

h: $\quad$ Entropy

$H$ : $\quad$ Blade height

I: $\quad h+0.5 C^{2}-u C_{\theta}$

$i$ : Point number

M: Distance along meridional curve or nondimensional meridional curve length

$m$ : Mass flow

M2: Absolute Mach number at impeller exit

Mr1: Relative Mach number at impeller inlet

Mr2: Relative Mach number of the primary zone at impeller exit

$N: \quad$ Rotational speed

$P$ : $\quad$ Control point

$p: \quad$ Diffuser leading edge pitch $=2 \pi r_{3} / Z$

$P R_{s}$ : Pressure ratio at surge

$P R_{d}$ : Pressure ratio at design point

$Q: \quad$ Volume metric flow

$S B: \quad\left(Q_{c}-Q_{s}\right) / Q_{c}$

$S M: \quad\left(P R_{s}-P R_{d}\right) / P R_{d}$

$t$ : $\quad$ Parameter

$U$ : Peripheral velocity

$W: \quad$ Relative velocity

$x, y$ : Coordinates

$Z$ : $\quad$ Number of vane or impeller blade.

\section{Subscripts}
1: Impeller inlet
2: Impeller exit
3: Diffuser inlet
c: Choke point
$s$ : Surge point
$o$ : Operation point
$p$ : Polytropic
$r$ : Radial direction.

\section{Greek}

$\beta$ : Blade angle from radial direction

$\phi$ : Flow coefficient based on compressor inlet condition $=Q /\left(N D^{3}\right)$

$\eta$ : Efficiency

$\sigma:$ Solidity $(=L / p)$

$\varepsilon$ : Turbulence eddy dissipation

$\varphi$ : Polytropic head coefficient $=H / u_{2}{ }^{2}$.

\section{References}

[1] W. Jansen and A. M. Kirschner, "Impeller blade design method for centrifugal compressors," NASA SP304, Part II, 1974.

[2] M. P. Boyce, Centrifugal Compressor: A Basic Guide, PennWell Corporation, Tulsa, Okla, USA, 2003.

[3] D. Japikse, Centrifugal Compressor Design and Performance, Concepts ETI, White River, Vt, USA, 1996.

[4] C. Xu and R. S. Amano, "On the development of turbomachine blade aerodynamic design system," International Journal of Computational Methods in Engineering Science and Mechanics, vol. 10, no. 3, pp. 186-196, 2009.

[5] M. Zangeneh, D. Vogt, and C. Roduner, "Improving a vaned diffuser for a given centrifugal impeller by $3 \mathrm{D}$ inverse design," in Proceedings of the ASME TURBO EXPO, pp. 1111-1122, Amsterdam, Netherlands, June 2002.

[6] N. K. Amineni and A. Engeda, "Pressure recovery in low solidity vaned diffusers for centrifugal compressors," 97-GT-472, 1997.

[7] Y. Senoo, H. Hayami, and H. Ueki, "Low-solidity tandemcascade diffusers for wide-flow-range centrifugal blowers," 83GT-3, 1983.

[8] C. Xu, R. S. Amano, and E. K. Lee, "Investigation of an axial fan-blade stress and vibration due to aerodynamic pressure field and centrifugal effects," JSME International Journal, Series $B$, vol. 47, no. 1, pp. 75-90, 2004.

[9] L. He and D. X. Wang, "Concurrent blade aerodynamic-aeroelastic design optimization using adjoint method," Journal of Turbomachinery, vol. 133, no. 1, Article ID 011021, 10 pages, 2011.

[10] T. Ghisu, G. T. Parks, J. P. Jarrett, and P. J. Clarkson, “An integrated system for the aerodynamic design of compression systems-part II: application," Journal of Turbomachinery, vol. 133, no. 1, Article ID 011012, 8 pages, 2011.

[11] T. Verstraete, Z. Alsalihi, and R. A. Van den, "Multidisciplinary optimization of a radial compressor for microgas turbine applications," Journal of Turbomachinery, vol. 132, no. 3, 7 pages, 2010.

[12] C. Xu and R. S. Amano, "A study on turbomachinery blade design and optimization procedure," International Journal for Numerical Methods in Fluids. In press.

[13] C. R. Weber and M. E. Koronowski, "Meanline performance prediction of volutes in Centrifugal compressors," in Proceedings of the ASME 31st Gas Turbine Conference and Exhibit, Dusseldorf, Germany, 1987.

[14] J. S. Arora, Introduction to Optimum Design, MCGraw-Hill, New York, NY, USA, 1998.

[15] D. Bonaiuti, A. Arnone, M. Ermini, and L. Baldassarre, "Analysis and Optimization of transonic centrifugal Compressor Impellers Using the Design of Experiments Technique," G T2002-30619.

[16] M. J. Harry, The Nature of Six Sigma Quality, Motorola University Press, Shaumburg, Ill, USA, 1997.

[17] C. Xu and R. S. Amano, "A hybrid numerical procedure for cascade flow analysis," Numerical Heat Transfer, Part B, vol. 37, no. 2, pp. 141-164, 2000.

[18] C. Xu and R. S. Amano, "Computational analysis of pitchwidth effects on the secondary flows of turbine blades," Computational Mechanics, vol. 34, no. 2, pp. 111-120, 2004.

[19] C. Xu and D. Valentine, "Diffuser for a centrifugal compressor,” US patent \# 7581925, 1997. 
[20] ANSYS, “Ansys multiphysics, Ver 11.0," ANSYS, 2007.

[21] C. Xu and M. Muller, "Development and design of a centrifugal compressor volute," International Journal of Rotating Machinery, vol. 2005, no. 3, pp. 190-196, 2005. 

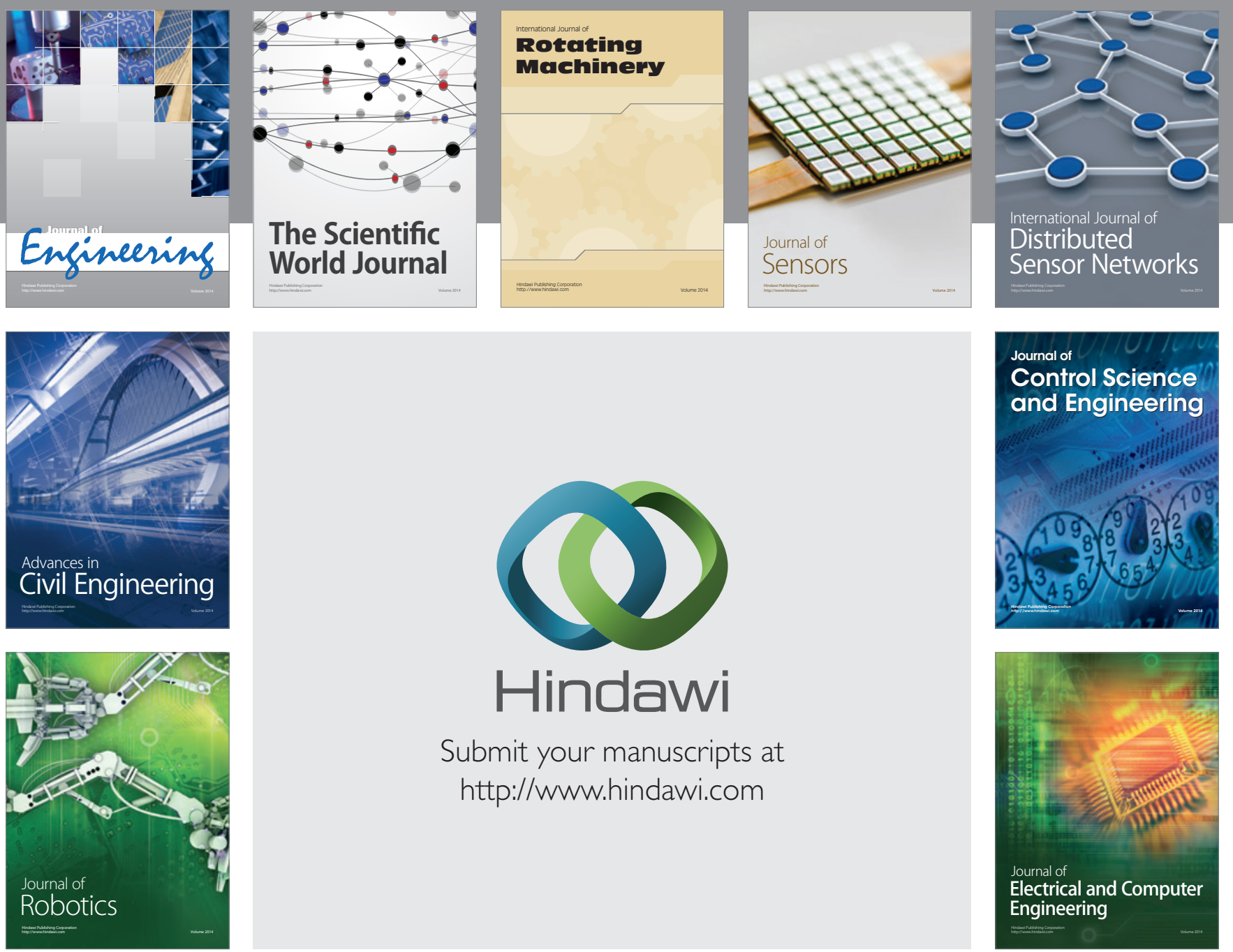

Submit your manuscripts at

http://www.hindawi.com
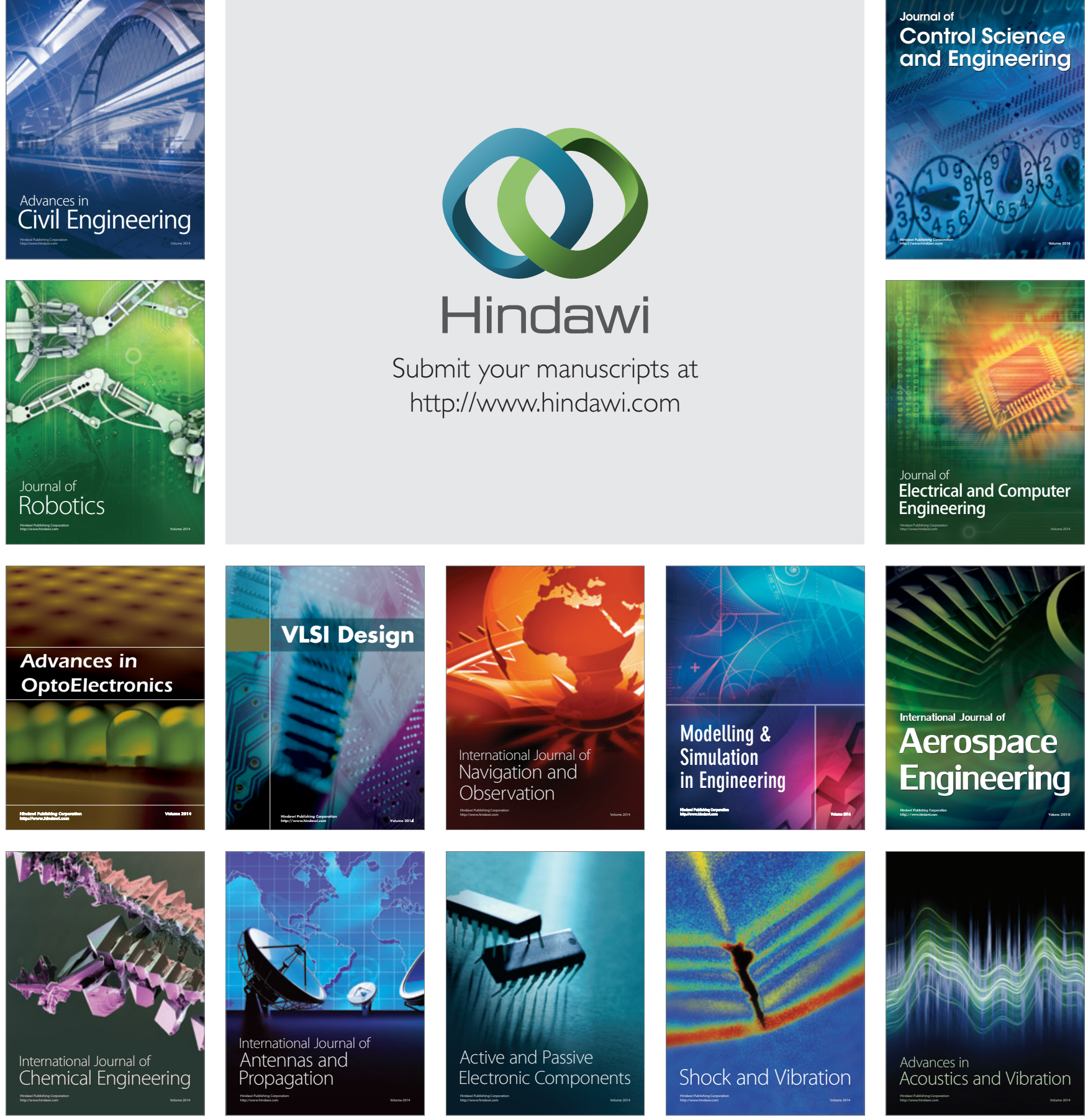